University of South Florida

DIGITAL COMMONS

Digital Commons @ University of

@ UNIVERSITY OF SOUTH FLORIDA

South Florida

QMaSC: A Handbook for Directors of

Quantitative and Mathematics Support Centers

USF Libraries

2016

\title{
31. Case Study: Peterson Quantitative Resource Center at St. Lawrence University
}

Michael Schuckers

St. Lawrence University

Follow this and additional works at: https://digitalcommons.usf.edu/qmasc_handbook

\section{Recommended Citation}

Michael E. Schuckers (2016), "Case Study: Peterson Quantitative Resource Center at St. Lawrence University", http://dx.doi.org/10.5038/9780977674435.ch31 in G. Coulombe, M. O’Neill, M. Schuckers (Eds.) A Handbook for Directors of Quantitative and Mathematical Support Centers, Neck Quill Press, http:// scholarcommons.usf.edu/qmasc_handbook.

This Case Studies is brought to you for free and open access by the USF Libraries at Digital Commons @ University of South Florida. It has been accepted for inclusion in QMaSC: A Handbook for Directors of Quantitative and Mathematics Support Centers by an authorized administrator of Digital Commons @ University of South Florida. For more information, please contact digitalcommons@usf.edu. 


\section{Case Study: Peterson Quantitative Resource Center at St. Lawrence University}

(c) Michael E. Schuckers, St. Lawrence University

प्र

\section{Introduction}

The Peterson Quantitative Resource Center (PQRC) at St. Lawrence University (SLU) was founded as the Quantitative Resource Center in August of 2007. SLU is a liberal arts college in Canton, New York with approximately 2400 students. The mission of the QRC has been to "facilitate, encourage, and develop quantitative reasoning, skills, and applications for the St. Lawrence University Community." As a consequence of this mission, the PQRC supports a variety of quantitative courses and initiatives across campus, not just mathematical ones. This wide net of campus support is intentional and is one that is meant to make our services and our programs broadly appealing.

A plan for a QMaSC at SLU had been in existence for many years prior to the founding of the PQRC; however, in those times when funds were available for the center, no appropriate space was attainable. In 2007, a new science building, the Johnson Hall of Science, housing the Biology, Neuroscience, Chemistry and Biochemistry programs, was completed. As a result, space was available for a QMaSC center in Bewkes Hall, a neighboring building where the Biology Department had previously been located. In 2008, the then QRC moved into a renovated space that was made

Suggested Citation: Michael E. Schuckers (2016), "Case Study: Peterson Quantitative Resource Center at St. Lawrence University", http://dx.doi.org/10.5038/9780977674435.ch31 in G. Coulombe, M. O’Neill, M. Schuckers (Eds.) A Handbook for Directors of Quantitative and Mathematical Support Centers, Neck Quill Press, http:// scholarcommons.usf .edu/qmasc_handbook.

This material is based upon work supported, in part, by the National Science Foundation under Grant DUE1255945. Any opinions, findings, and conclusions or recommendations expressed in this material are those of the author(s) and do not necessarily reflect the views of the National Science Foundation 
possible by a generous donation from Martie and Gregg Peterson. The PQRC was renamed for them in 2012 on the occasion of Martie's 50th class reunion.

The PQRC is currently located in Valentine Hall, which is the primary classroom building for the sciences at St. Lawrence University. The exact location is at the corner of two highly trafficked hallways, outside of the Mathematics, Computer Science and Statistics Department office, and is a very visible location for that part of campus. The PQRC has approximately $2500 \mathrm{sq}$. $\mathrm{ft}$ of space, which is divided into several parts. The main space is an open room of approximately $1500 \mathrm{sq}$. ft that has movable furniture that can be arranged into tables or spread apart for a seminar. Just off the main space we have a small library where we try to keep reference materials as well as copies of textbooks for more popular courses. There is an office for the assistant director and two group study spaces off of the main room. Outside the entrance to the PQRC there is a lounge that has a couch, two love seats and several work tables. This lounge was intentionally designed to be a welcoming and casual entrance to the PQRC and has proved to be very popular. Finally, there is a seminar room that seats up to 12 that the PQRC shares with the Department of Mathematics, Computer Science, and Statistics. The department has scheduling priority during the day, and the PQRC has scheduling priority in the evenings.

St. Lawrence University is a private, liberal arts college in northern New York. We have a strong Department of Mathematics, Computer Science, and Statistics which regularly produces 40 to 50 majors per year with approximately the same number of minors. That said, we are part of a campus that has a long tradition of the liberal arts taken very broadly. Until recently, St. Lawrence did not have a quantitative graduation requirement, but instead had a mathematics or foreign language requirement. An impetus for the creation of the PQRC was a finding that graduating seniors at St. Lawrence felt less confident in their quantitative reasoning skills relative to when they started. In this environment, we began the work of the PQRC by taking a broad approach to quantitative matters. We emphasized and encouraged these topics in a variety of ways. One example of this early in the life of the PQRC was the distribution to SLU faculty of books with quantitative content, but with that content not being the main focus. Among these books were Andrew Gelman's Red State, Blue State, Rich State, Poor State and Edward Tufte's Visual and Statistical Thinking: Displays of Evidence for Making Decisions. Faculty who received these books were asked to come to a small group discussion of the books, led by another non-PQRC affiliated faculty member. We have also for several years now had a graphic feature called "On Q" in the weekly student newspaper that covers some topic of relevance from a quantitative viewpoint. For example, one of these was a bar chart showing the ten most popular candies at Halloween. The point of these features is to give examples of uses of quantitative material that is informative and appropriate.

In 2012, the Faculty of St. Lawrence passed a quantitative and logical reasoning requirement as part of a new set of general education requirements. This change will impact the role of the 
PQRC on campus and we have begun planning for this new environment.

\section{Center organization and services}

The PQRC at St. Lawrence is a peer-led drop-in tutoring center. The staff is composed of between 20 and 25 undergraduate students, a director, and an assistant director. The Director has been a faculty member from the Mathematics, Computer Science, and Statistics Department who receives a course reduction each semester for their role at the center. The usual faculty teaching load is three courses per semester. The author of this chapter has been the only director since the founding of the PQRC. The work of the director is to oversee the staff, set the direction for the center, and interact with faculty and administration. The director reports to the Dean of Academic Affairs. The PQRC also has an advisory board of faculty and staff that meets at the end of the semester and gets a report from the director regarding accomplishments over the course of the semester. The original advisory board was quite large with representation from nearly every department or program with quantitative content. This was done to create awareness and support for the center. Recently, though, the board has shifted into a smaller group to assist the director in transitioning to the new general education requirements.

The Assistant Director is a graduate student in the Education department at SLU who reports to the director. The Education Department at SLU is the only department to offer graduate degrees and certifications. The assistant director is paid hourly and gets a tuition remission for six courses per academic year. The expectation is that this individual will work approximately 15 to 20 hours per week in the PQRC during the academic year. Summer duties vary depending upon need. The role of the assistant director is to help manage the center primarily through coordination of the day-to-day operations of the center, which includes tasks of staff scheduling and payroll. Both the director and the assistant director take active roles in the training and hiring of our staff.

The staff of undergraduate mentors has as their primary duty the one-on-one mentoring of drop-in students. Mentors report to both the assistant director and the director. The mentors have a variety of backgrounds, but they must have both quantitative and communication skills. Since the PQRC supports not just math, computer science, and statistics courses, but also economics, biology, and psychology courses, among others, we need a staff that has a range of backgrounds. In addition to their work as mentors, we also have our staff run many of the workshops that we lead. In the past, these workshops have covered topics such as trigonometry, logarithms, LaTeX, designing a poster, Excel, and the quantitative reasoning section of the GRE. Our general model for these workshops is to have the first couple of versions designed and run by the director and/or the assistant director. Beginning with the second or third iteration, we include mentors in the process and have them involved in developing materials and running the workshops. We then transition the workshops to be run as much as possible by the mentors. Some care and judgment are necessary 
in organizing mentor-led workshops, as some of our more formal faculty members prefer not to have students lead their classes; however, there are several benefits to having the mentors run these workshops. Foremost among these benefits is the experience the mentors gain from the planning and execution of the workshops.

\section{$3 \quad$ Staffing, Hiring and Training}

The staff for the PQRC, as mentioned in the previous section, consists of about twenty-five undergraduates, an assistant director, and a director. The assistant director's position is normally for two years, though in one exceptional case it was extended to three years. As noted above, there has been only one director for the PQRC since its founding. The PQRC mentors, who comprise the rest of the staff, are usually hired, and remain at the PQRC until they graduate. The PQRC is generally open from 10 am to $11 \mathrm{pm}$ on Monday through Thursday, from 10 am to $3 \mathrm{pm}$ on Friday and from $2 \mathrm{pm}$ to $11 \mathrm{pm}$ on Sundays. We ensure that there are never fewer than two mentors working at a given time. The number of mentors on staff varies with mentee attendance but generally there is a period in the evening when four or five mentors are on staff with a ramp up and ramp down period of fewer mentors working around those busiest hours. We have an electronic sign-in protocol, so that we are able to track when students come into the center. Initial staff scheduling decisions are done at the first staff meeting at the beginning of the semester, based upon sign-in traffic data from previous semesters. At that same meeting we set the weekly semester schedule, so that each mentor has the exact same hours every week during the semester. This has two benefits. First, mentors have a consistent schedule that is built around their classes and activities, and second, mentees who find a particular mentor to be helpful know when they can find these mentors again. When mentors have an exam or practice which conflicts with their schedules, we have a listserv that allows mentors to communicate the need for someone to cover a given shift. We also use this listserv for sharing of general center information. Mentors are expected to check their email regularly for updates.

Hiring for PQRC mentors is typically done every spring semester for the following year. Occasionally it is necessary to also hire in the fall semester for the spring semester. Before each hiring process begins, we do an internal assessment of the number and types of students that we will need. If necessary, we will try to recruit applications for specific areas, such as psychology, economics, or computer science, where we may need additional coverage. Our process for hiring is to ask applicants to submit a form (located in appendix of chapter), along with a copy of their unofficial transcript. After these applications have been submitted, we review each of them, solicit reference from relevant faculty and match qualifications with needs. We then interview a subset of these applicants. Our interview process is 30 minutes long and consists of two parts. In the first part, the candidate meets with the assistant director, the director, or both to discuss his or 
her background, interest in the PQRC, and any questions about the position. In the other half of the interview, candidates meet with two to four current mentors and are presented with a simple topic from a course they have previously taken, usually Calculus I or Statistics. They are asked to explain a problem as they would to someone taking that class. Also, in this half of the interview candidates have an opportunity to ask mentors about the work environment at the PQRC. Once all the candidates have been interviewed, all of the interviewers convene to discuss each candidate and to rank the candidates. This ranking is tentative, and further discussion usually takes place between the director and assistant director before final offers are made.

Hiring for the assistant director follows a roughly similar process. Once the approval to hire is given by our human resources department, applications are taken and reviewed by a committee. In this case, the committee is usually comprised of the director, the chair of the Mathematics, Computer Science and Statistics Department, two or three other quantitative faculty members, and two PQRC mentors. Once qualified candidates have been interviewed by each member of the committee, a decision is made, and the candidate is offered the position. This protocol much more closely matches a faculty search at SLU.

Initial training of mentors is done at the beginning of their first semester at the PQRC. Typically we have two training sessions. The first covers the basic rules and expectations of working at SLU and of working at the PQRC including PQRC disciplinary policies. We have created a 20-page manual of rules and procedures for our mentors. We give them a copy of this manual and cover the topics in that manual during the first session. The second session deals with how to have a good mentoring session with a student. We talk about creative ways to engage students and how to solve problems that may arise. One of the highlights of the second session is a panel that we create of current experienced mentors. The director and assistant director lead the first part of the panel discussion, and then there is a closed door session without administrators, where new mentors can ask experienced mentors about working at the PQRC. The second session also has a bit of role playing to practice some circumstances that arise commonly while working. Each of these sessions lasts approximately 2.5 hours.

Further training is done at our bi-weekly, with candy - Take $5^{\mathrm{TM}}$ is the official candy of the PQRC - staff meeting which have traditionally been held on Sunday evenings. These all-hands-on meetings are nominally required and typically last about 40 minutes. Students are paid for their attendance at these meetings. During this time we cover incidents that have occurred since the last meeting and do additional training on professionalism in the workplace or ways to engage with different learning styles, for example. We also view these meetings as opportunities for team building. We have intentionally placed a good deal of emphasis on building our staff into a cohesive unit, since we feel that the more comfortable our staff is with each other, the more inviting the PQRC will feel. To that end we also have a social committee of mentors who schedule events for mentors such as a barbeque, a bowling night, or a formal. 


\section{Community Interactions}

As our mission states, we consider our community to be the entire St. Lawrence Community. Certainly our primary focus has been and will continue to be the support of academic work at St. Lawrence University. To that end, we interact extensively with faculty who are teaching quantitative courses at St. Lawrence. This interaction takes several different forms. At the beginning of each year we interact with faculty in biology, chemistry, and physics as we run refreshers for some high school mathematics topics. Upon the request of some faculty, we set our schedule to have certain mentors available at certain times so that there is support for their courses at appropriate moments, such as within the evening hours before weekly quizzes. We have made classroom visits to discuss data visualization and to introduce Excel. Some faculty leave copies of solutions to homework or assignments with us, and we add them to our library. We also have longer-running interactions with courses that take place over the course of the semester which involve multiple visits to classes or specific workshops. As the director, I also consult with faculty on their courses. One of the benefits - and there are drawbacks, too - to having a faculty member as a director is that faculty consider you a peer and are willing, in most cases, to consider your opinion.

The director of the PQRC is also a member of a group at SLU called 'Critical Literacies' which includes the director of the writing center, the director of the arts technology center, and the head of the science library, among others. Much of the people in this group are involved, to one degree or another, in academic support; in some ways it is a support group for academic support. The bi-weekly meetings are chaired by the Dean of Academic Affairs. These meetings often focus on ways to ensure that students and faculty are getting the support to carry out their roles on campus.

At a couple of times over the course of the PQRC we have helped local community organizations with quantitative matters. We have helped a local bank analyze patterns of traffic at their different branches and we have assisted a local center for at-risk youth to analyze a survey of their clientele. We view our participation in these projects as being a good citizen in our community. There are probably more such projects that we could be doing, but we do not currently have the time or resources to make them a reality.

\section{Assessment at the PQRC}

Assessment at the PQRC takes a couple of forms. First, we measure the number of drop-in visits we receive each semester; we view this as one important measure of what we do. When students sign in, we acquire some information about them and about why they are visiting the PQRC on this particular occasion. The PQRC now has approximately 3300 student drop-in visits per year. Second, there is the assessment of how our mentors perform. After each visit, mentees are encouraged to complete an online evaluation of their experience. They are asked to rate the quality 
of the mentor, and the quality of the session, and they have the opportunity to give comments. The ratings are on a one to five scale with five being the highest rating. Our form for mentor evaluation can be found at: http://web.stlawu.edu/qrcint/evaluation.php. Over the past couple of years our average ratings have been about 4.8 for both mentors and session quality; however, we only get about $15 \%$ of students who sign in to complete an evaluation of their session. In many cases, this is due to mentees coming in only to use our resources, specifically the books in our small library, or because they were in a hurry to leave. There is some self-selection bias in our summaries, since those who do not complete the form are potentially not as satisfied with their experience at the PQRC as those that do. One area on which we need to improve is in evaluating this aspect of our operation. Third, we are assessed by our advisory board of faculty and staff. Twice a year, at the end of each semester, the director covers the goals for the upcoming semester, presents a summary of activities for the current semester and gets feedback on the performance of the PQRC from this board. This is the only form of external assessment that the PQRC has had.

It is worth noting here that with the implementation of the new general education requirement at St. Lawrence, we have convened a new advisory board of six faculty members to consider the future of the PQRC and its role on campus. The previous board had one member from each department that had some quantitative content as well as representatives from Information Technology and our Rhetoric and Communication Initiative. To facilitate the work of this new advisory board, we wrote a three page memo describing the current work of the PQRC and asked this group to consider the following questions:

1. What should be the mission of the PQRC for the next 5 to 10 years?

2. What should be the specific objectives of the PQRC over that time period?

3. What changes, if any, would you recommend to the structure of the PQRC in order to fulfill the mission and to achieve the objectives outlined in 1) and 2)?

4. What specific methods should the PQRC leadership undertake to fulfill the mission and to achieve the objectives outlined in 1) and 2)?

We hope that the answers to these questions will provide a basis and direction for leading the PQRC for the foreseeable future.

\section{Acknowledgements}

I would like to thank Martie and Gregg Peterson for their generosity which has allowed the PQRC to prosper. I also wish to acknowledge the tremendous Assistant Directors that the PQRC has had since 2007. These are (reverse chronologically): Kerrin Ehrensbeck, McKayla Nuffer, Alli Morrow, and Tim Morse. They have been immeasurably helpful in the success of the PQRC. I am lucky to have worked with such wonderful people and luckier to call them friends. 


\section{Appendix: PQRC Mentor Application Form}

PQRC Mentor Job Description: PQRC mentors work with students to develop their quantitative skills (usually in the context of a particular quantitative course). Additionally, mentors will occasionally be involved in workshops, presentations, research, and community outreach. The characteristics that we are looking for in our mentors include a strong quantitative background (math major not required), good communication skills, patience, enthusiasm, and the ability to work well in a dynamic group situation. Mentors will be expected to work a minimum of 5 hours per week at the PQRC as well as attend bi-weekly staff meetings.

Name

Class

CMR\#

Email

Cell Phone \#

Major(s)/Minor(s)

Advisor(s)

1) Quantitative Course History Please include all relevant quantitative courses (math, statistics, computer science, economics, psychology, physics, biology, chemistry, geology) AND attach an unofficial copy of your SLU transcript. Please include courses in which you are currently enrolled.

\begin{tabular}{|l|l|l|l|l|l|}
\hline Dept. & Course\# & Professor & Semester & Year & Final Grade \\
\hline & & & & & \\
\hline & & & & & \\
\hline & & & & & \\
\hline & & & & & \\
\hline & & & & & \\
\hline & & & & & \\
\hline & & & & & \\
\hline & & & & & \\
\hline & & & & & \\
\hline & & & & & \\
\hline & & & & & \\
\hline & & & & & \\
\hline & & & & & \\
\hline & & & & & \\
\hline & & & & & \\
\hline & & & & & \\
\hline & & & & & \\
\hline & & & & & \\
\hline
\end{tabular}

\section{Continued on back}


2) Campus Work History

\begin{tabular}{|l|l|l|l|l|}
\hline Position & Dept & Supervisor & Semester & Year \\
\hline & & & & \\
\hline & & & & \\
\hline & & & & \\
\hline & & & & \\
\hline & & & & \\
\hline & & & & \\
\hline
\end{tabular}

3) Do you have any formal or informal tutoring experience? (If so, please elaborate)

4) Have you used software in courses that you feel comfortable helping students with? (If so, please elaborate)

5) Additional Faculty/Staff References (Please include contact information)

6) What is the best way to contact you over summer break?

If you have any questions about the PQRC or about this application, please refer to the PQRC website www.stlawu.edu/qrc OR contact us at qrc@stlawu.edu. 